Article

\title{
An Approach for Feedforward Model Predictive Control of Continuous Pulp Digesters
}

\author{
Moksadur Rahman *(1), Anders Avelin and Konstantinos Kyprianidis \\ School of Business, Society and Engineering, Mälardalen University, Box 883, 72123 Västerås, Sweden \\ * Correspondence: moksadur.rahman@mdh.se; Tel.: +46-(0)21-10-1594
}

Received: 9 August 2019; Accepted: 4 September 2019; Published: 6 September 2019

\begin{abstract}
Kappa number variability at the continuous digester outlet is a major concern for pulp and paper mills. It is evident that the aforementioned variability is strongly linked to the feedstock wood properties, particularly lignin content. Online measurement of lignin content utilizing near-infrared spectroscopy at the inlet of the digester is paving the way for tighter control of the blow-line Kappa number. In this paper, an innovative approach of feedforwarding the lignin content to a model predictive controller was investigated with the help of modeling and simulation studies. For this purpose, a physics-based modeling library for continuous pulp digesters was developed and validated. Finally, model predictive control approaches with and without feedforwarding the lignin measurement were evaluated against current industrial control and proportional-integral-derivative (PID) schemes.
\end{abstract}

Keywords: pulp and paper; Kappa number; pulp digester; modeling; feedforward; predictive control

\section{Introduction}

Pulp and paper mills convert cellulosic fibers, mostly wood, into pulp and various types of paper products. At present, more than half of the globally produced pulp comes from the Kraft or sulfate pulping process. In the Kraft pulping process, the continuous pulp digester is one of the most critical components. The digester is a complex heterogeneous reactor in which white liquor-an aqueous solution of sodium hydroxide and sodium sulfide-reacts with wood chips comprising mainly of cellulose, hemi-cellulose and lignin, to remove lignin and subsequently free wood fibers. Due to the naturally varying feedstock, long and variable residence time, insufficient measurements and complex physico-chemical characteristics, the digester requires sophisticated control strategies to ensure safe and economically viable operations. Hence, an integrated approach of model-based process control as proposed by the authors in earlier articles [1,2], is highly advantageous. Here, we focus on the use of near infrared (NIR) spectroscopy-based lignin content measurement coupled to a dynamic process model as an enabler for feedforward model predictive control (FFMPC). A brief literature review on modeling and predictive control of pulp digesters is presented in the subsequent sections.

\subsection{Modeling of Pulp Digester}

The success of a model-based control approach is highly dependent on the accuracy of mathematical models used to capture the process behavior. Thus, developing a robust model that can closely depict the digester behavior is of the utmost importance. The complex nature of the delignification process makes the modeling of this highly heterogeneous system particularly challenging. The continuous pulp digester is a pressurized cylindrical vessel with a varying diameter along the vertical direction, which could be 50 to $80 \mathrm{~m}$ high [2,3]. Not only do different phases coexist in the vessel but also significant mass transfer occurs. Moreover, the reaction kinetics are highly nonlinear and discontinuous. To maintain different temperatures in different zones of the digester there are several sets of screens that extract 
part of the free liquor from the different axial positions and reinject it after heating and strengthening by addition of fresh liquor. Both concurrent and counter current of free liquor and chips coexist inside the digester, which adds further complexity to the flows inside the digester. From a computational point of view, this introduces model discontinuity and non-convexity $[4,5]$.

Considerable effort has been expended in the past few decades to model continuous pulp digesters with varying levels of complexity based on different approaches to reaction kinetics, diffusion and chip-bed compaction. Two groups of widely used dynamic models are known as the Purdue models and Gustafson models. While the former was developed to deal with the complex chemical composition of the wood substance, the latter emphasized a more detailed description of delignification coupled to diffusion phenomena. The Purdue model was originally developed by Smith and Williams [6]; where the wood substance was represented as five different components reacting in parallel, and the digester was approximated by a series of continuous stirred-tank reactors (CSTRs). This approach was followed and further developed by other researchers [7-10]. On the other hand, the first version of the Gustafson model appeared in the mid-eighties, where the Kraft cooking was modeled as three successive phases: Initial, bulk and residual, and the wood substance was represented as two components [11]. This model was further developed by other researchers [12,13]. Grénman et al. [14] combined the work of Purdue, Gustafson and Andersson to model delignification kinetics by considering the influence of wood anisotropy and internal diffusion. Pourian et al. [15] presented a CFD model for the physical structure of a pulp digester and prediction of the continuous chemical reactions inside the digester. In more recent work, Nieminen et al. [16] proposed a new kinetic model of lignin and carbohydrates degradation. Delignification was described with varying degrees of sophistication, and carbohydrates degradation is modeled based on the reaction mechanism of peeling, stopping and alkaline hydrolysis. Andersson et al. [17] and Nieminen and Sixta et al. [18] performed comparative studies on the accuracy of several kinetic models of the pulp digester. In these works, kinetic models were applied to simulate a well-controlled laboratory-scale batch digester. The results indicate that the Purdue model has the best structure, weighing the complexity and computational efficiency. It was able to follow the trajectory of the cook with higher accuracy, given that a good adjustment of its parameters was performed.

The previous works cited here have made a valuable contribution towards the understanding and modeling of the continuous pulp digester. However, implementation of such dynamic models for online application and control needs further modification and simplification to improve robustness. Furthermore, there is a need for developing a generic pulp digester library that could be used for customizing the models accounting for digesters with different dimensions, configurations and types.

\subsection{Predictive Control of the Pulp Digester}

The main objective of the continuous pulp digester is to produce pulp with specific quality (mostly the Kappa number that is a measure of the residual lignin content in the produced pulp) while maintaining the targeted production rate. Generally, pulp digesters are designed to meet these objectives. However, in reality, the process variables often deviate from their prescribed limits, mainly due to external disturbances and inherent process variabilities. This is where the control system has a role in actively maneuvering the process so that the process variables stay within the prescribed limits. Due to the complex nature of the process, the continuous pulp digester requires multi-variable process control. When it comes to multi-variable process control, model predictive controller (MPC) is widely accepted as a superior control method over the classical methods. Additionally, MPCs are often preferred because of their ability to deal with long delays and inverse or non-minimum-phase zero responses that are quite common in continuous pulp digesters. Contrarily, inexpensive ways of obtaining complex process models, coping with uncertainties due to model errors or unmeasured disturbances, and withstanding process faults are few challenges that MPCs need to overcome to ensure a widespread industrial usage.

MPC refers to a range of control algorithms that explicitly utilize plant measurements to predict the future behavior of the plant with the help of a process model. At every control step, the MPC 
attempts to optimize the future behavior of the plant by evaluating future sequential control moves over the prediction horizon. The controller then only executes the first step of the previously evaluated optimal control moves. The entire process is repeated again before the next control move. In reality, the MPC computes the optimal control moves by solving a constrained finite-horizon optimization problem in which the objective functions make use of model predictions. Readers are referred to a very extensive review by Mayne [19] for further details on MPCs.

Controlling the continuous pulp digesters have been studied extensively over the years, mostly focusing on the $\mathrm{H}$-factor, Kappa number, extraction rest alkali, chip level and blow-line consistency control [20-23]. Kappa number control has been the subject of most studies because of its direct impact on the pulp quality and economics of the mill. However, controlling the Kappa number is a challenging task, mainly because all the main control manipulation are performed in the top part of the digester, but the Kappa number is only measured at the outlet of the digester. Due to the long transport delay of $4-5 \mathrm{~h}$ between these points, feedback controllers are not very effective [22]. Furthermore, blow-line Kappa number is affected by a large number of process variables. Hence, achieving stable Kappa control using univariate controllers seems inappropriate. Apart from MPCs, a wide variety of control approaches, such as reduced dimension control (RDC), smith predictor and generic algorithms have been investigated for Kappa number control [24-26]. MPCs are preferred over other model-based techniques because they are well suited to run on standard industrial distributed control system (DCS) hardware [23]. They also have the most flexible formulation, since a wide variety of process model forms (e.g., state-space, transfer function, zero-pole-gain, etc.) can be integrated and direct handling of constraints is possible [27].

The use of MPC for the continuous pulp digesters has been investigated in several studies, in both academia and industry. In an early work, Michaelsen and Christensen [28] used a simplified version of the Purdue model to compare the performance of an MPC against a proportional-integral-derivative (PID) controller for Kappa number control of a Kamyr digester. The authors claimed that only three state variables (temperature, effective alkali (EA) and residual lignin) are sufficient to capture the dynamics of the plant without significant performance degradation. Several other researchers also investigated the possibility of controlling the blow-line Kappa number of continuous pulp digesters. Taha and Dumont [29] examined the control of three sensitive control loops, namely the Kappa number, H-Factor and digester level, and found that majority of the undesirable variabilities originated from the interaction of these loops, making classical PID schemes inefficient. They used a simplified version of the Hatton model and a controlled auto-regressive integrated moving-average process model as the basis for an MPC to control the digester level; this also stabilized the Kappa number. Robert [30] focused on the selection of different modeling techniques, i.e., reaction kinetics, gain scheduling and adaptive time-series modeling, based on different control applications, i.e., Kappa number control, automatic grade change and level control. The author argued that gain scheduling and process-linearization methods should always be preferred over an online estimator unless the process gain changes unpredictably. Doyle and Kayihan [27] asserted that tighter control of the pulp quality can be achieved by controlling the Kappa profile along the digester length rather than the blow-line Kappa number. The authors used a subspace-identification method to develop an MPC to reduce Kappa variability. Doyle et al. [31] investigated a similar approach for automatic grade change. Padhiyar [32] examined Kappa-profile control by utilizing a multi-rate extended Kalman filter-based nonlinear MPC. The authors concluded that the target Kappa profile was achievable only in 'normal' conditions and profile may not be achievable in the presence of model-plant mismatch, unmeasured disturbances and input limitations. In a later publication, Padhiyar and Bhartiya [33] proposed a lexicographic optimization-based MPC that enforces priorities to achieve the blow-line Kappa target when the target Kappa profile is unachievable due to the aforementioned reasons. Wisnewski and Doyle [34] analyzed performance of three different MPCs—each employing a different plant model, with varying degrees of complexity - based on their ability to reject stochastic, measured and unmeasured disturbances. According to the simulation results, MPCs based on both linear- and nonlinear-fundamental models 
provided a better closed-loop response in comparison to the linear-empirical model, while all of them were proficient at rejecting the stochastic composition disturbances. A relatively recent work by Luppi et al. [35] compared a centralized MPC strategy against a decentralized PID control strategy to evaluate the global dynamic and economic performance of a Kraft pulping mill. The authors reported remarkable economic improvements compared with decentralized control by employing an MPC for the digester and limekiln zone. Trung and Allison [36] proposed the use of Fourier-transform NIR (FT-NIR) spectroscopy-based black liquor chemical composition measurement for advance control of the pulp digester. Badwe et al. [22] reported significant reduction in end-point Kappa number variability with the help of an MPC by utilizing a Kappa soft sensor based on the chip temperature profile throughout the digester.

Research related to continuous pulp digester control by employing MPCs has attracted substantial attention from the research community and industry. Nevertheless, Kappa number variability at the digester outlet is still a major concern of the pulp and paper industry. Pulp with a variable Kappa number at the digester outlet can be lower in strength, more difficult to bleach and may lead to complications in downstream processes. With the rapid advances in computational power, the use of nonlinear-physics-based digester models for model predictive control is increasing. Integrating advanced measurement techniques with MPC can provide tighter control of the continuous pulp digester. However, reliable measurement devices targeting digester control are not well developed [36]. Conventionally, a reliable measurement of chip moisture and lignin content, white liquor EA and sulfidity, weak black liquor residual alkali (RA) and end-point Kappa number, has mostly been by laboratory testing. Advanced measurement techniques for reliable online measurement of important process parameters are emerging [37-40]. Thus far, the majority of these new sensors have mainly been used for process monitoring rather than process control.

\subsection{Objectives and Contributions}

Although modeling and predictive control of the continuous pulp digester have been studied extensively in the literature, there is a considerable gap in the area of integrating emerging state-of-the-art measurement techniques to improve the performance of the predictive controllers. This paper focuses on an innovative approach of feedforwarding the NIR spectroscopy-based lignin-content measurement to an MPC in order to minimize the blow-line Kappa variability. To achieve this, a generic modeling library for the continuous pulp digester is developed in the open source object oriented modeling tool OpenModelica. The developed model is then validated against measurements from a continuous pulp digester from the BillerudKorsnäs Gävle integrated pulp and paper mill, located in Sweden. Finally, a multi-variable MPC scheme with feedforwarding lignin-content measurement is explored and compared to MPC without feedforwarding and a decentralized PID controller. A linearized model based on the physical model is identified using the subspace-identification technique for the MPC implementation.

Two primary research questions, based on the literature study, guided this investigation: (1) Can a generic object-oriented modeling library be used to model commercial pulp digesters? and (2) to what extent can digester control be improved by feedforwarding the online wood chip lignin measurement to an MPC?

The paper is organized as follows. First, Section 2 provides a detailed description of the continuous pulp cooking process. Second, the necessary technical details for the developed digester model are presented in Section 3. Section 4 describes the model tuning procedure in detail, followed by model validation. Results from both steady state and dynamic simulations are presented. Section 5 summarizes digester controllability analysis along with a detailed description of the developed MPC scheme. The performance of the proposed scheme is evaluated with help of simulation studies in Section 6 . The paper concludes with Section 7 that also discusses the directions for future research.

\section{Process Description}

A simplified diagram of a single-vessel continuous digester is shown in Figure 1a. After pre-processing, i.e., debarking, washing, chipping and screening, wood chips are transported to 
the chip bin by conveyor belts [41]. The wood chips are then pre-steamed at atmospheric pressure to remove air, open up the pores and make it possible for chemicals to impregnate the chips. Chips are transported to a screw-conveyor steaming vessel by a low-pressure feeder and then injected into a high-pressure feeder. A circulating-feed liquor transports the chips from the high-pressure feeder to the top of the digester. White liquors are also introduced at the top of the digester according to the required EA to wood ratio. Black liquors are added to maintain targeted liquor to wood ratio in the digester. Chips move downwards in the cylindrical digester mainly due to the density difference between the impregnated chips and the surrounding liquor, as well as a fluid drag mechanism and gravitational force. A higher chip level is intentionally maintained at the top of the digester to increase the effect of the gravitational force.

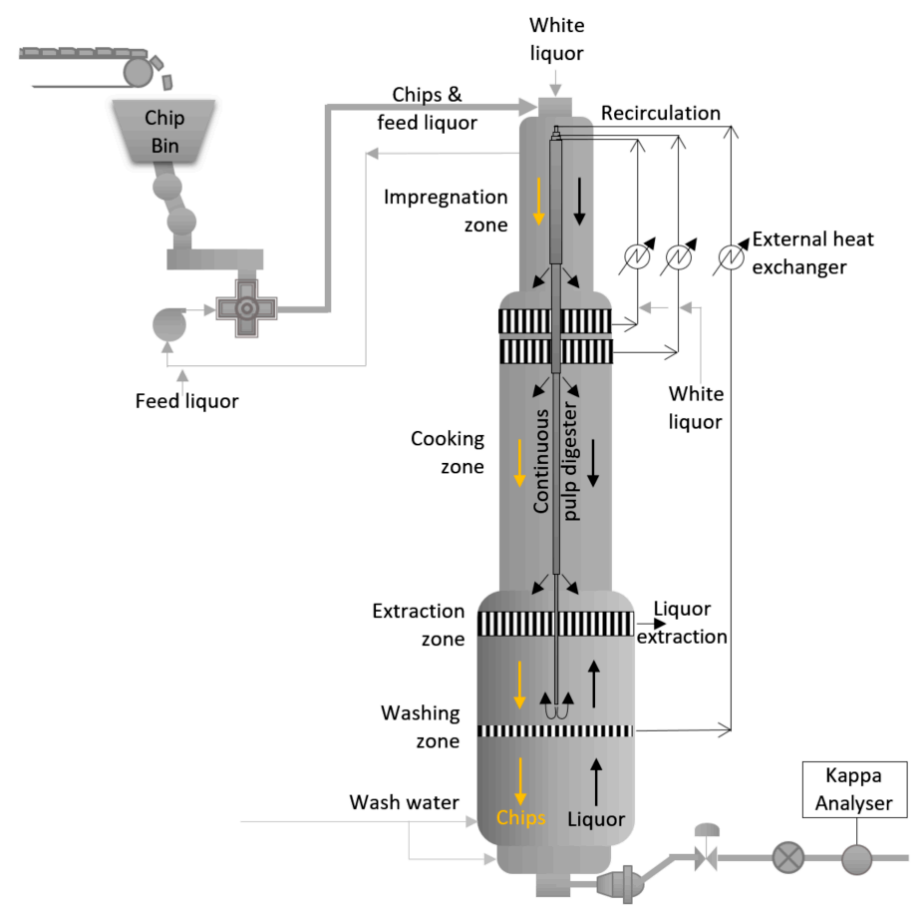

(a)

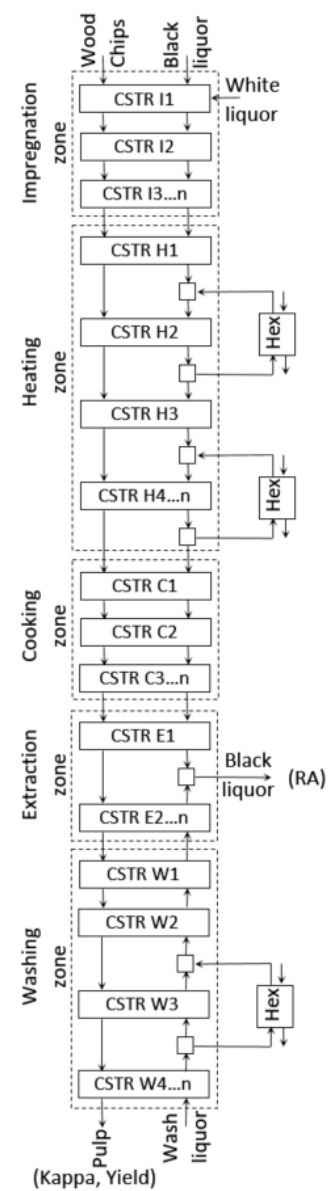

(b)

Figure 1. (a) Schematic of a continuous digester process flow and (b) conceptual model architecture.

The first zone in the top of the digester is the impregnation zone; here, wood chips are impregnated with the cooking liquor by means of penetration and diffusion. The typical temperature in this section is between $115^{\circ} \mathrm{C}$ and $125^{\circ} \mathrm{C}$. Initial delignification already starts in the impregnation zone: Around $20 \%-25 \%$ of the total lignin is dissolved here. After liquor impregnation, the chips are rapidly heated in the heating zone to the cooking temperature between $150^{\circ} \mathrm{C}$ and $170{ }^{\circ} \mathrm{C}$ depending on the wood type (softwood or hardwood) [42]. The heating zone usually has one or more liquor-circulation screens along its outer edge. Liquor is extracted through these screens and circulated back to the center of the digester via a central pipe discharge device after heating or fresh liquor make-up. Desired cooking conditions inside the digester, i.e., temperature and liquor strength, are maintained by these recirculation loops. Under the heating zone is the concurrent cooking zone, where most of the delignification reactions take place. The rate of the delignification reaction is mainly dictated by liquor concentration, cooking time 
and temperature. In general, the cooking time is controlled by the chip flow rate, and the degree of cooking/delignification is controlled by the recirculation temperature and fresh liquor make-up. After the cooking zone, the spent liquor is separated and extracted through a set of extraction screens in the extraction zone. Next is the counter-current washing zone, where cold and diluted wash liquor is injected at the bottom of the digester to slow down the delignification reaction [43]. The remaining liquor is extracted from the chips here, thereby preserving the fiber properties. A recirculation loop with heating is added in the washing zone to avoid re-precipitation of lignin onto the pulp fibers at lower temperature. The cooked pulp is extracted at the digester bottom. The quality of the resulting pulp at the blow-line is expressed by the Kappa number [44].

\section{Model Formulation}

A lumped approximation is used to model the continuous pulp digester. The digester is segmented into a series of infinitesimal CSTRs (Figure 1b) with axial distribution of conserved quantities due to the plug-flow motion of the chips and free liquor. As a simplifying assumption, radial transport phenomena are neglected. Temporal variation of conserved quantities within each CSTR is derived by applying conservation laws that result in a set of coupled non-linear partial differential equations (PDEs) in Euler's formula.

Figure 2 shows a conceptual outline of a CSTR from the cooking zone of the digester. Each CSTR is assumed to contain three phases: Solid phase, entrapped liquor phase and free liquor phase. The solid phase refers to the wood substance, the entrapped liquor phase refers to the liquor in the pores of the wood chips, and the free liquor phase refers to the liquor surrounding the chips. The combined solid and entrapped liquor phases are referred as the chip phase. The solid phase is assumed to consist of five components: Fast-reacting lignin, slow-reacting lignin, cellulose, araboxylan and galactoglucomannan. Both entrapped liquor and free liquor phases are assumed to consist of seven components: Active EA, passive EA, active hydrosulfide (HS), passive HS, dissolved lignin and dissolved carbohydrates. The chemical reactions are assumed to occur only between solid and entrapped liquor phases, whereas diffusion mass transfer occurs between entrapped and free liquor phases. Moreover, dynamic and thermal equilibrium between each of the aforementioned pairs of phases are also taken into account. For the model description, subscripts $s, e$ and $l$ are used to denote solid, entrapped and free liquor phases, respectively. Subscript $i$ is used to denote a series of different components in each phase, and subscript $j$ denotes the corresponding control volume.

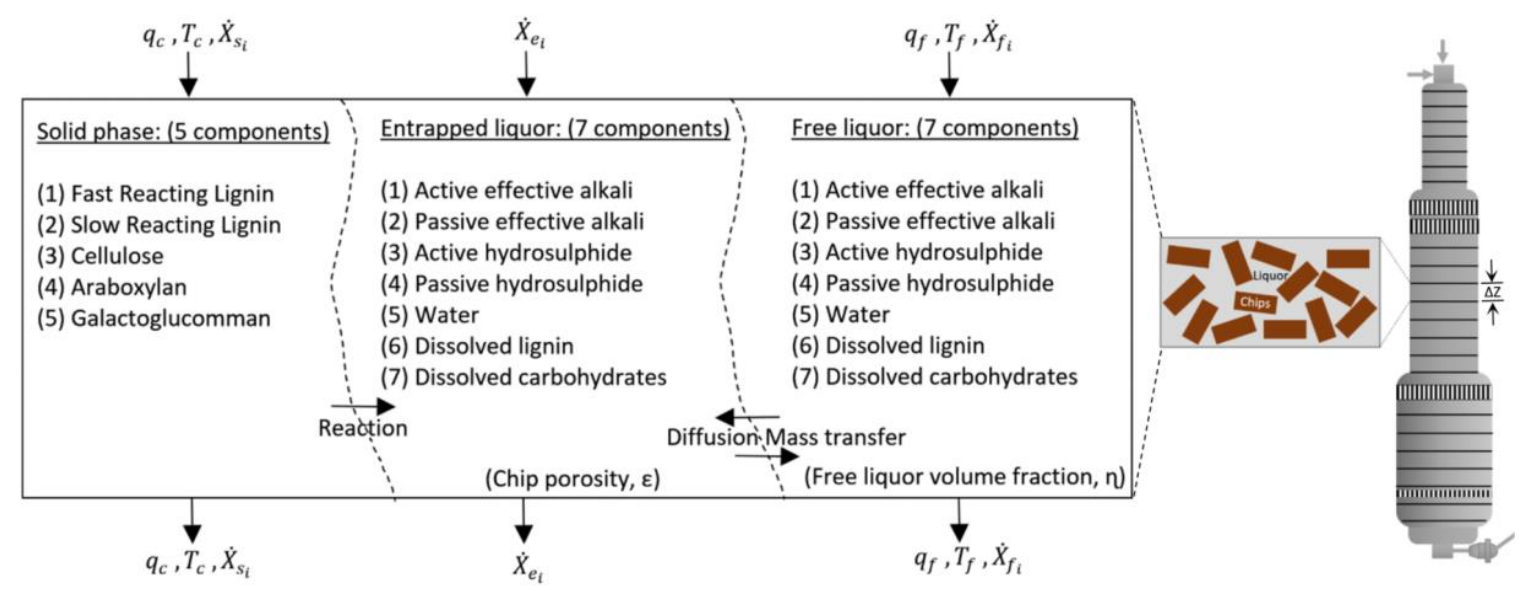

Figure 2. Conceptual outline of a continuous stirred-tank reactor (CSTR) located in the cooking zone. EA: Effective Alkali, HS: Hydrosulphide (adapted from $[9,45]$ ).

Modeling the reaction kinetics essentially forms the mathematical foundation for the entire digester model. The reaction rates of solid phase components $\left(r r_{s_{i}, j}\right)$ were calculated using the kinetic model developed by Christensen et al. [46], 


$$
r r_{s_{i}, j}=\left(k_{1, i, j}\left[O H^{-}\right]+k_{2, i, j}\left[O H^{-}\right]^{0.5}\left[H S^{-}\right]^{0.5}\right)\left(X_{s_{i}, j}-X_{s_{i}}^{\infty}\right),
$$

where $X_{s_{i, j}}$ and $X_{s_{i}}^{\infty}$ represent the concentrations of instantaneous and unreacted solid phase components. The reaction rate constants $k_{1, i, j}$ and $k_{2, i, j}$ are temperature dependent, and expressed according to the Arrhenius law,

$$
\begin{aligned}
& k_{1, i, j}=A_{1, i} \exp \left(\frac{-E_{1, i}}{R T_{\mathcal{c}}}\right) . \\
& k_{2, i, j}=A_{2, i} \exp \left(\frac{-E_{2, i}}{R T_{\mathcal{c}}}\right) .
\end{aligned}
$$

Here, $A_{1, i}$ and $A_{2, i}$ represent the Arrhenius coefficients, while $E_{1, i}$ and $E_{2, i}$ represent activation energies. $T_{c}$ and $R$ are the chip temperature and universal gas constant. The reaction rates of entrapped liquor components $\left(r r_{e_{i}, j}\right)$ are linked to the reaction rates of solid phase components by the stoichiometric coefficients $\left(b_{i, k}\right)$,

$$
r r_{e_{i}, j}=\sum_{k=1}^{5} b_{i, k} r r_{s_{k}, j} .
$$

The values of the Arrhenius coefficients, activation energies and stoichiometric coefficients for both softwood and hardwood are well documented in Wisnewski et al. [8]. The chip porosity increases along the digester length due to the chemical reaction, and the free-liquor volume fraction decreases because of the gradual chip-bed compaction. The chip-bed compaction is taken into account by a compaction factor $\left(f_{c}\right)$, which is the ratio between the volume of chip column in a pile outside and inside the digester.

Hence, the free liquor volume fraction $\left(\eta_{j}\right)$ was defined as,

$$
\eta_{j}=1-f_{c}\left(1-\eta_{\text {pile }}\right) .
$$

Here, the free liquor volume fraction outside the digester $\left(\eta_{\text {pile }}\right)$ is a constant. For simplicity, an approach similar to Fernandes et al. [47] for the compaction factor $\left(f_{c}\right)$ was adopted. Based on the literature, it is reasonable to assume that the compaction factor decreases linearly along the digester length until the bottom section of the digester where it is constant $[47,48]$.

Therefore, the compaction factor,

$$
f_{c}=f(h)=\left\{\begin{array}{c}
0.032 h+1.01 h<h_{r e f} \\
2.16 h \geq h_{r e f}
\end{array},\right.
$$

where $h_{r e f}$ is the reference height of the digester, at which the chip compaction reaches the maximum and stays constant to the digester bottom. The chip compaction also affects the chips' residence time in the digester, since it slows the downward motion of chips as they proceed through the digester.

Finally, the conservation equations, i.e., energy, mass and momentum balances were considered to calculate the individual concentrations of the components and temperatures in each CSTR.

The Kappa number, one of the main pulp-quality parameters, is available from both the online analyzer and laboratory measurement. In the model, the Kappa number was calculated using the following definition:

$$
\kappa=\theta_{L k} * \frac{X_{s, 1}+X_{s, 2}}{\sum_{i=1}^{5} X_{s, i}}
$$

where $\theta_{L k}$ is the empirical regression coefficient that relates the Kappa number with the lignin fraction of the produced pulp. Indisputably, Kappa number shows the linear correlation with both the lignin fraction of the pulp and the hexenuronic acids that form in the xylan during Kraft cooking. However, authors following the Purdue approach were able to neglect the contribution from hexenuronic acids by regressing laboratory pulping data, and used a value of 653.595 for $\theta_{L k}$ for softwoods [8-10]. 
By using this model, it is possible to estimate Kappa numbers at different positions in the digester, which can also be used as a soft sensor. Moreover, the yield at the blow-line was defined as the ratio between the amount of wood solid components at the blow-line and the amount of wood solid components at the digester inlet.

$$
\gamma=\frac{\sum_{i=1}^{5} X_{s, i}(\text { blow line })}{\sum_{i=1}^{5} X_{s, i}(\text { digester inlet })}
$$

To implement the model in OpenModelica, a generalized CSTR segment was created with all the required mathematical equations. Additional components such as mixtures, heat exchangers and connectors are also created. All the digester zones, i.e., impregnation, heating, cooking, extraction and washing zones were formed by connecting CSTRs in series. Eventually, each of the zones, mixtures and heat exchangers were connected together to form the complete digester model (Figure 3). The modeling library was built as a generic library so that different pulp digesters can be modeled by connecting different components together.

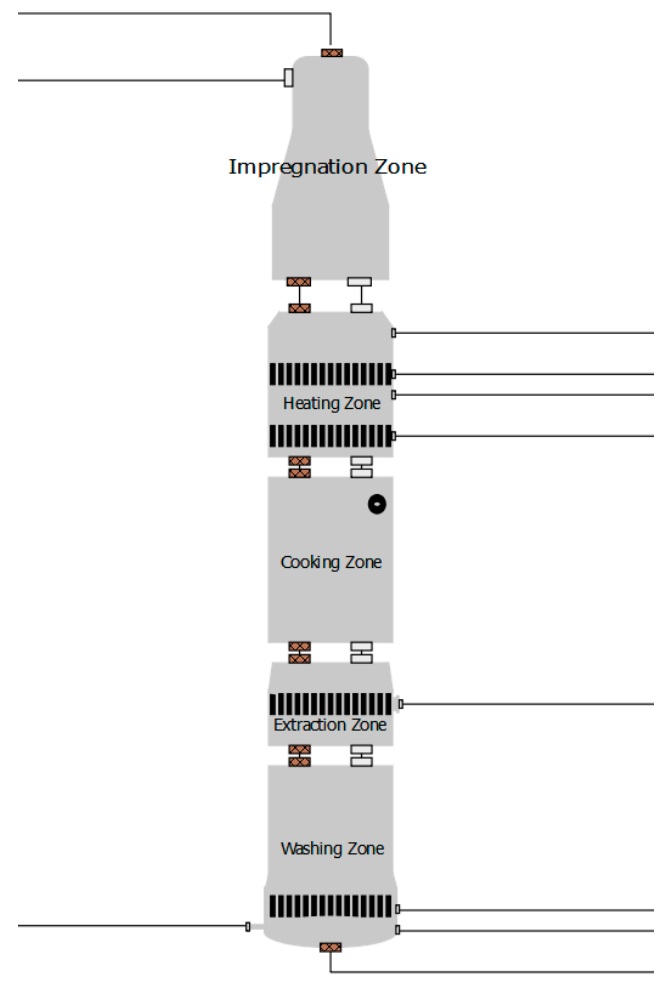

(a)

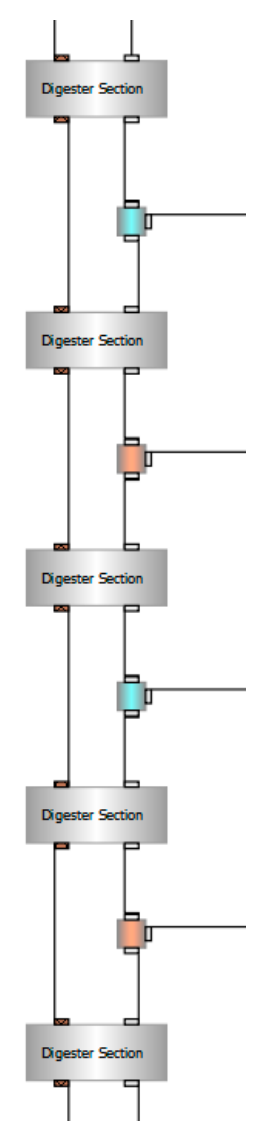

(b)

Figure 3. Object-oriented model of continuous pulp digester in OpenModelica. (a) Complete digester and (b) impregnation zone.

The model inputs are the flow rate and temperature of the wood chip, flow rates and temperatures of the different liquor streams (i.e., white liquor and black liquor inflows at the digester top, upper and lower heating circulations, wash circulation and wash inflows), EA and sulfidity of white liquor and blow-line flow. On the contrary, the model outputs are the predicted Kappa number and yield at the blow-line, flow rate, temperature and RA at the extraction point, liquor temperatures before the heat exchangers and the retention time of the digester. 


\section{Solution and Validation}

Being conceptually more complex, physical models are capable of capturing the process behavior in a wider range of operating conditions. However, without proper tuning these models often result in discrepancy between model outputs and real-plant responses. In order to minimize the model-plant mismatch, mapping of digester constants and estimation of a set of parameters was carried out in this work. The dimensions and positions of instruments in the commercial digester were obtained from the digester drawings and piping and instrumentation diagram (P \& ID) and inserted into the model. The parameters in a physical model can have specific physical implications that can be very useful for the controller design and process diagnostics. Therefore, a careful selection of parameters was carried out for this estimation task. Among all the model parameters, a set of three parameters corresponding to reaction rates was selected for estimation. These were stoichiometric coefficients for EA and HS consumption and the reaction-rate multiplier.

To estimate these parameters, three model outputs that are highly linked to the intensity of reaction i.e., reaction rates, were selected: Blow-line Kappa number, yield and RA of extraction liquor. The Kappa number corresponds to the remaining lignin in pulp, whereas the yield, a measure of economic performance of the process, is the amount of pulp produced from a given amount of raw material, expressed as a percentage. Finally, the RA of extraction liquor is a measure of remaining alkali that is not consumed during the reaction. For the digester under consideration, online measurements of Kappa number and RA are available, whereas measurements of yield are available intermittently via lab measurements. Each of these quantities is directly related to the reaction rate. The higher the reaction rates, the lower the Kappa number, yield and RA. In this work, predefined ranges for each of the selected parameters (adopted from the literature [8]) are considered so that the physical meanings of these parameters are not violated. Finally, few suitable operating points close to the nominal digester operation were selected to tune the model.

To analyze the steady-state response of the tuned digester model, online measurements corresponding to a stable operating point of the digester were used as model inputs. The evolution of all major process variables along the digester length was studied. However, only Kappa number, EA, temperature and free liquor velocity are presented here in terms of spatial variation. As shown in Figure 4a, the Kappa number initially increases slightly before it starts to decrease in the impregnation zone. The initial increase is attributed to the rapid consumption of carbohydrates relative to lignin. The Kappa number decreases rapidly in the heating and cooking zones, driven mainly by the elevated temperature and the higher concentration of chemical in the entrapped liquor phase. As the reaction is quenched by cooler and diluted washing liquor in the washing zone, the Kappa number stabilizes. The change in EA is reflected in Figure $4 \mathrm{~b}$, where the solid and dotted lines represent the entrapped liquor and free liquor respectively. The EA curves for the entrapped and free liquor meet each other in the impregnation zone as the cooking liquor penetrates into the chip, and decrease quickly in the cooking zone as EA is consumed during the reactions. The variation of temperature and free liquor velocity in the digester zones is shown in Figure 4c,d. The increase in temperature in the heating zone is a result of the recirculation heaters, and is linked to the corresponding velocity peaks as shown in the free liquor velocity curve. Subsequently, the temperature increase in the cooking zone is associated with the exothermic nature of the delignification reaction. The temperature rise in the cooking zone due to the heat of reaction is in line with the value reported in literature [49]. 
(a) Kappa Profile

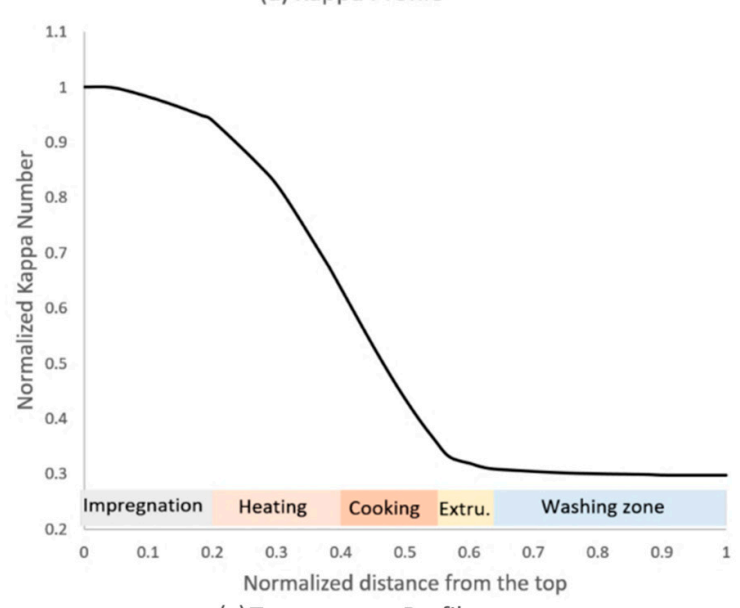

(c) Temperature Profile

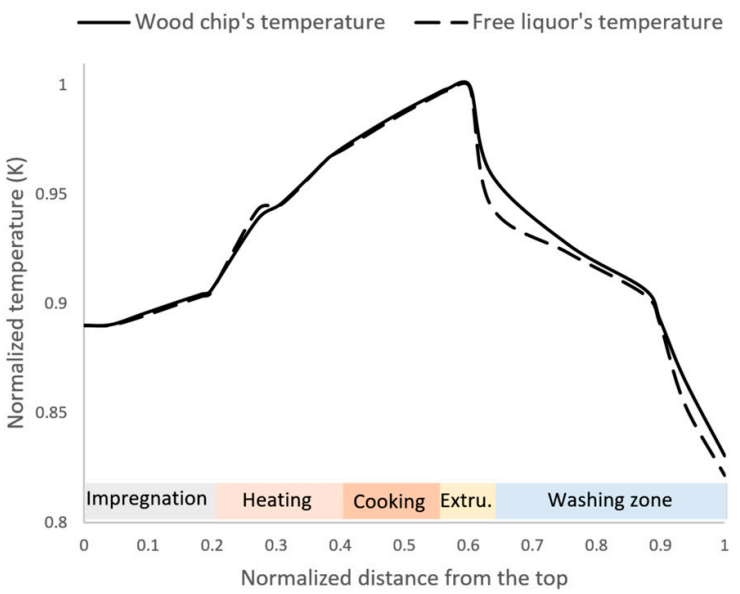

(b) Effective alkali (EA) Profile

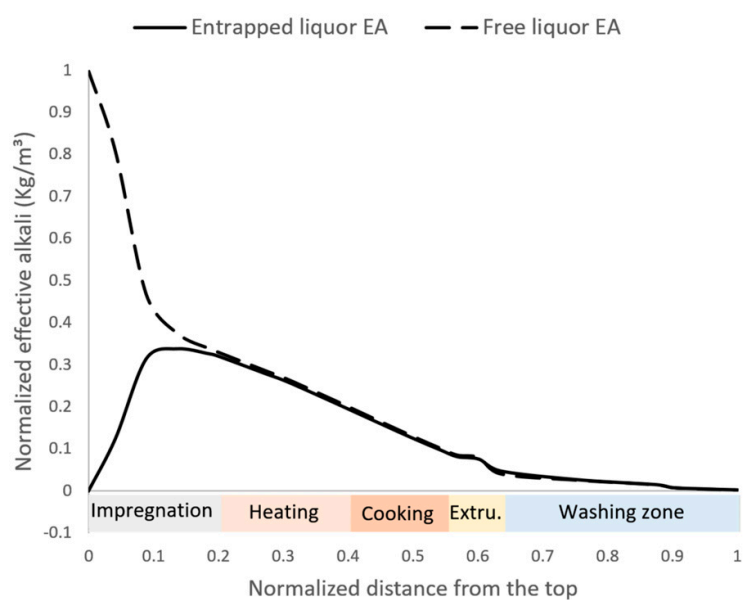

(d)Freeliquor Velocity Profile

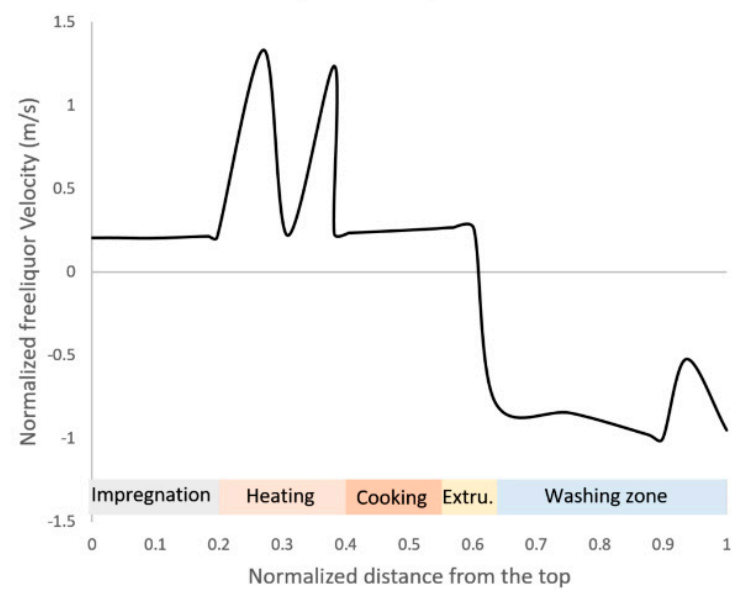

Figure 4. Spatial development of major process variables in the direction of chip flow. (a) Kappa number, (b) EA, (c) temperature and (d) free liquor velocity.

To validate the predictive capability of the model, a simulation was performed with actual plant measurements representing two weeks of digester operation as inputs of the model. For validation purposes, it is always preferable to maintain the production rate close to the nominal value and avoid abrupt changes in process parameters. However, due to the operational practicalities this was not possible. The simulated Kappa number of produced pulp, RA of the extraction liquor and temperature of the free liquor before the recirculation heat exchangers are compared with the actual plant measurements in Figure 5. The plant measurements used here were collected at $15 \mathrm{~min}$ sampling frequency. All the missing data and unrealistic values (such as negative chip flowrates, negative sulfidity and out-of-range temperatures) were replaced with last-known reliable values, which may explain some of the model-plant mismatches. Further mismatches could be due to process faults (such as clogged screen, channeling or hang-ups), which cannot be validated presently due to a lack of fault-related data. There may also be mismatches due to the shortcomings of the model. As Figure 5 shows, the simulated profile follows the plant measurements for the majority of the time. The most influential sensor fault affecting the prediction capability of the model is the chip flow rate. The chip flow rate reading from the sensor was negative between hours 133 and 158, which could explain the deviation of the simulated Kappa number from the actual measurement during this period. The modeling error for Kappa number and RA is mostly between $0 \%$ to $5 \%$, with the exception of a few peaks. The modeling for temperatures error is less than $2 \%$ for the majority of the time. Given the complexity of the pulping process, the 
level of accuracy of the model in capturing trends and deviations is satisfactory for simulation and control purposes.
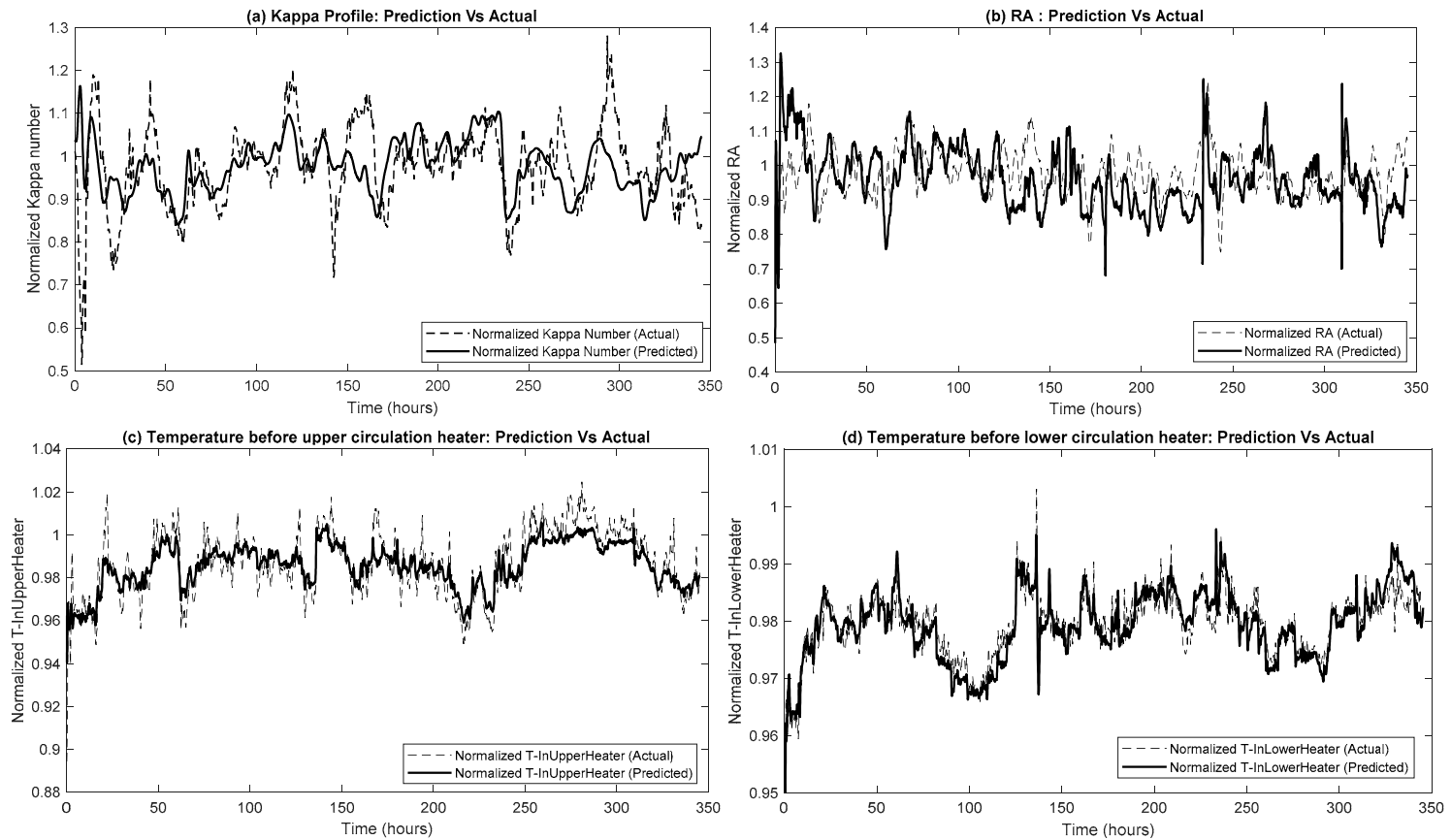

Figure 5. Comparison between actual and predicted. (a) Kappa number, (b) residual alkali (RA) of extraction fluid, (c) temperature before upper recirculation heat exchanger and (d) temperature before lower recirculation heat exchanger.

\section{Pulp Digester Control}

\subsection{Controllability Analysis}

Wood chip lignin and moisture contents are two major process disturbances that most affect the end-point Kappa number. These are inherent properties of the wood chips. Therefore, the control system should be designed to reject such disturbances. The white liquor flow rate and EA, and the temperatures of recirculation heat exchangers are two further potential manipulated variable pairs for controlling the end-point Kappa number. Nonetheless, changing the EA of white liquor is not directly possible as this value is an output from the chemical recovery plant. It can be changed indirectly by changing the ratio of white and black liquor at the digester inlet.

A series of step tests was performed on the model around the nominal operating point of the digester to analyze the system dynamics and its controllability. These step tests are useful for understanding the influence of different variables on the controlled outputs, and therefore have an important role on the selection of manipulated variables. In particular, it is important here to investigate the influence of chip lignin and moisture content, white liquor flow rate and EA, and heating temperature of upper and lower heat exchangers on the end-point Kappa number, as depicted in Figure 6. Typically, the response of the end-point Kappa number to any step change can be characterized by an initial delay followed by a long rise or fall time. The initial delay is associated with the retention time of the digester, while the gradual rise or fall time is associated with the slow transient response that reflects the slow nature of the thermo-chemical delignification process. As can be seen from Figure 6a, the step change in lignin content shows a faster response with a small overshoot compared with the step change in moisture content. It is important to note that the step change in moisture content shows non-minimum-phase zero behavior. For example, with a $+5 \%$ increase in moisture content, the Kappa number initially decreases before it starts to increase again and reach a steady-state value. This can lead to internal instability in the system and thus creates severe problems for conventional control systems. Figure $6 b, c$ shows that a step 
change in white liquor flow rate and EA has a shorter time delay but a longer rise or fall time in Kappa number, when compared with temperatures of recirculation heat exchangers. However, step change in temperature results in a faster overall response of the Kappa number. Therefore, temperature of recirculation heat exchangers may perform better as the manipulated variable. In practice, only one of the recirculation heat exchanger temperatures is used as a manipulated variable while the temperature of the other is kept constant.
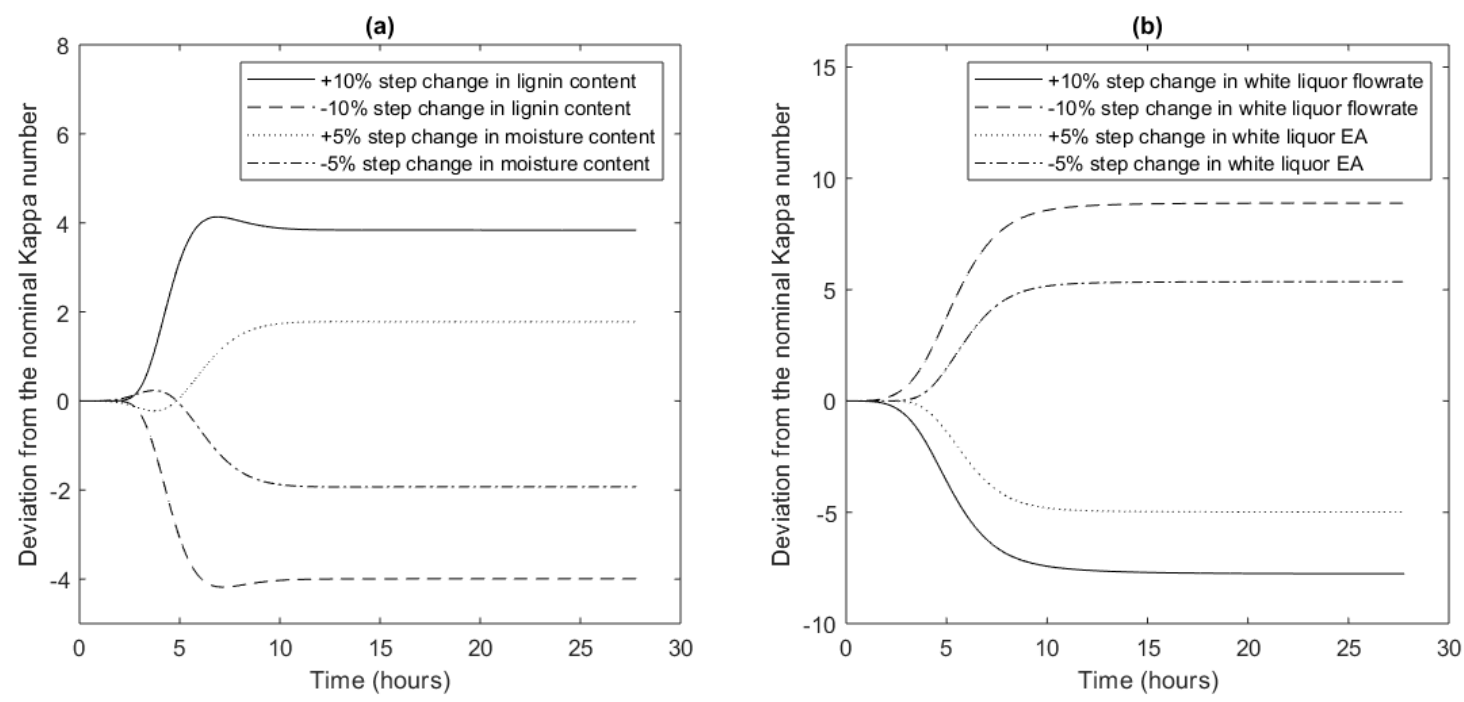

(c)

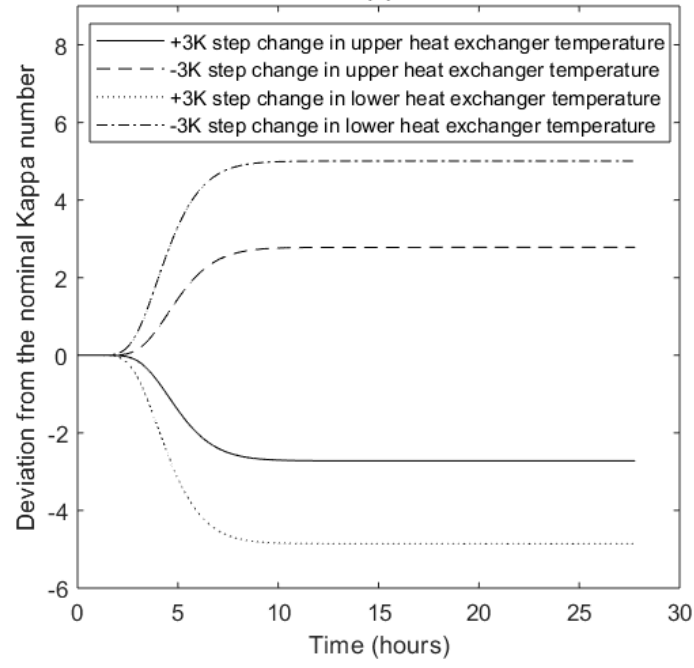

Figure 6. Step change in (a) wood chips lignin and moisture content, (b) free liquor flowrate and EA and (c) upper and lower recirculation heat exchanger temperature.

\subsection{Model Predictive Control}

As discussed in Sections 1.2 and 5.1, there are a number of control problems associated with pulp digesters, the most significant of which is the multi-variable nonlinearity of the main controlled output, i.e., end-point Kappa number. Nevertheless, ensuring robust control of the digester during normal operation as well as when extreme process changes are imposed is a priority. Accordingly, we proposed a feedforward MPC framework, as shown in Figure 7, to tackle these problems. The proposed framework is based on the real-time measurement of lignin content of the wood chips and feedforwarding it to an MPC. The online measurement of lignin content is based on the NIR spectroscopic measurement. The theoretical background and experimental validation of such an NIR soft sensor for wood chip lignin content measurement can be found in numerous literature [50,51]. By soft sensing and feedforwarding 
one of the major process disturbances, i.e., lignin content, the MPC will able to follow the Kappa number set point more closely. The digester model uses the eight other measured disturbances along with the soft-sensor measurement to predict the Kappa number. By comparing the predicted Kappa number with the reference set point, future error is calculated. The optimizer uses the future error to calculate the optimum set-point trajectory. However, only the first full set of calculated manipulated variables are sent to the DCS. These manipulated variables are assigned as instantaneous set points for the lower-level controls.

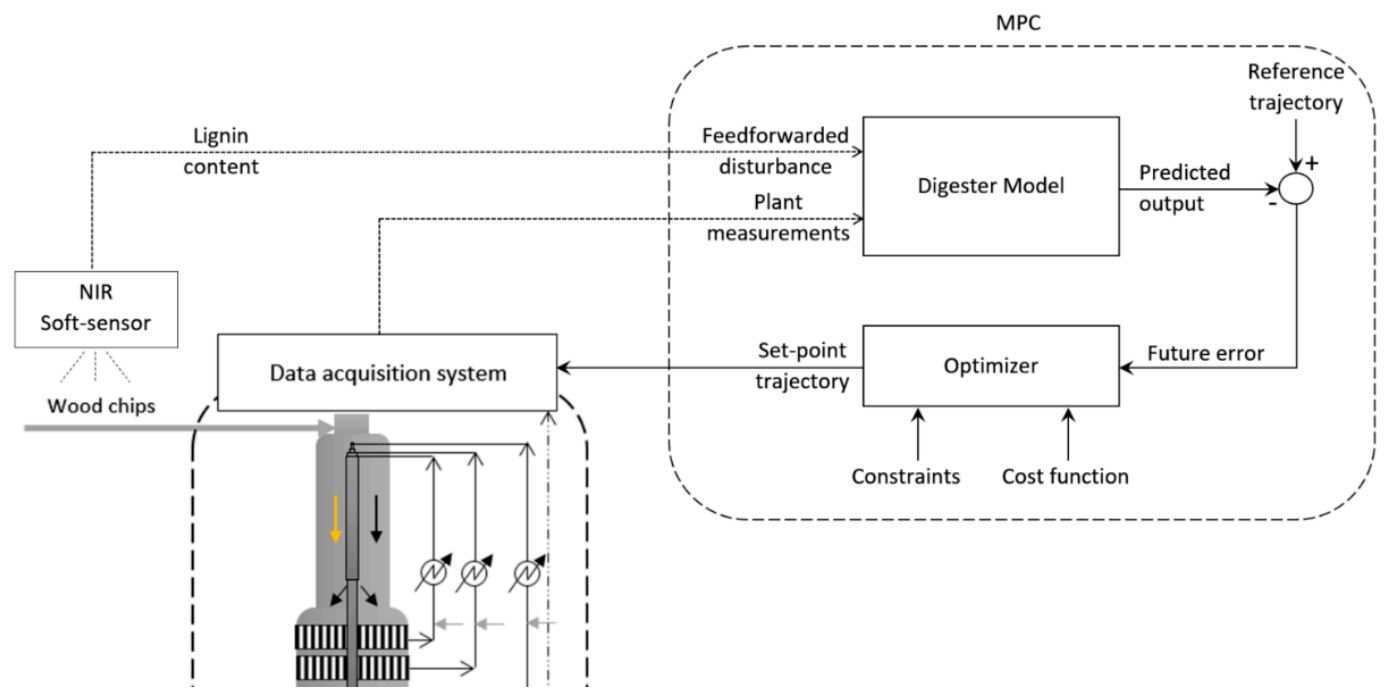

Figure 7. Scheme of feedforward model predictive control (MPC) for continuous pulp digester.

To develop the MPC, a reduced order state space model was developed by the subspace identification (SSID) method from the validated dynamic model of the pulp digester. Ten sets of simulated data with a one minute sampling rate were generated. The first nine sets of data were used for model identification and the tenth dataset used for model validation. The process inputs (i.e., disturbances and manipulated variables) were changed as random steps within the allowable range and the process outputs (i.e., Kappa number and RA) were recorded using the validated dynamic model. By utilizing the numerical subspace state-space system identification (N4SID) algorithm in MATLAB's System Identification Toolbox, a state-space model was identified, with the following form:

$$
\begin{gathered}
x_{t+1}=A x_{t}+B u_{t}+K d_{t}, \\
y_{t}=C x_{t}+D u_{t}+d_{t},
\end{gathered}
$$

where $x$ is the state variable vector, $u$ is the input vector, $y$ is the output vector and $d$ is the disturbance vector. $A, B, C$ and $D$ are state-space matrices, and $K$ is the disturbance matrix. $D$ is fixed to zero by default, which assumes that at least one delay exists between the input and the output.

As shown in Figure 8, the identified state-space model performs reasonably well in comparison to the dynamic model.

The next step in MPC development is the definition of the optimization problem, which is widely referred as the optimizer and consists of an objective function (or cost function) and multiple constrains. The optimizer formulation ensures the fulfillment of the control objectives without violating the constraints. The optimizer does this by utilizing the process model to predict the future outputs and continuously comparing them with the set points. Furthermore, the optimizer also imposes different levels of punishment schemes for quick changes in the manipulated variables. By doing so, the optimizer prevents extreme changes in manipulated variables that can be either costly or impossible to achieve. Consequently, the constraints are classified as hard or soft constrains. In reality, the cost function is 
a mathematical expression that is either minimized or maximized to find a best solution among all possible feasible solutions. In this paper, the cost function refers to the minimization of the sum of squared errors between the desired set point and the actual trajectory of the controlled output, with an additional penalty imposed on rapid changes in the manipulated variables.

$$
\min f(u)=\sum_{i=1}^{p}\left(y(u)-y_{\text {set }}\right)^{T} W\left(y(u)-y_{\text {set }}\right)+\sum_{i=0}^{c-1} d u_{i}^{T} S_{i} d u_{i} .
$$

Subject to constraints:

$$
\begin{gathered}
u_{\min }<u<u_{\max } \forall i \in[0, \mathrm{c}-1], \\
\Delta u_{\min }<\Delta u<\Delta u_{\max } \forall i \in[0, \mathrm{c}-1],
\end{gathered}
$$

where $y(u)$ is the vector for actual measured outputs at the different time steps over the prediction horizon of $p$ samples and $y_{\text {set }}$ is the vector for output set points for the same time steps. $W$ and $S_{i}$ are the weight functions used to increase the importance of specific variables at given instances. In this minimization, a sequence of manipulated variables $u$ is calculated over a control horizon with m samples.

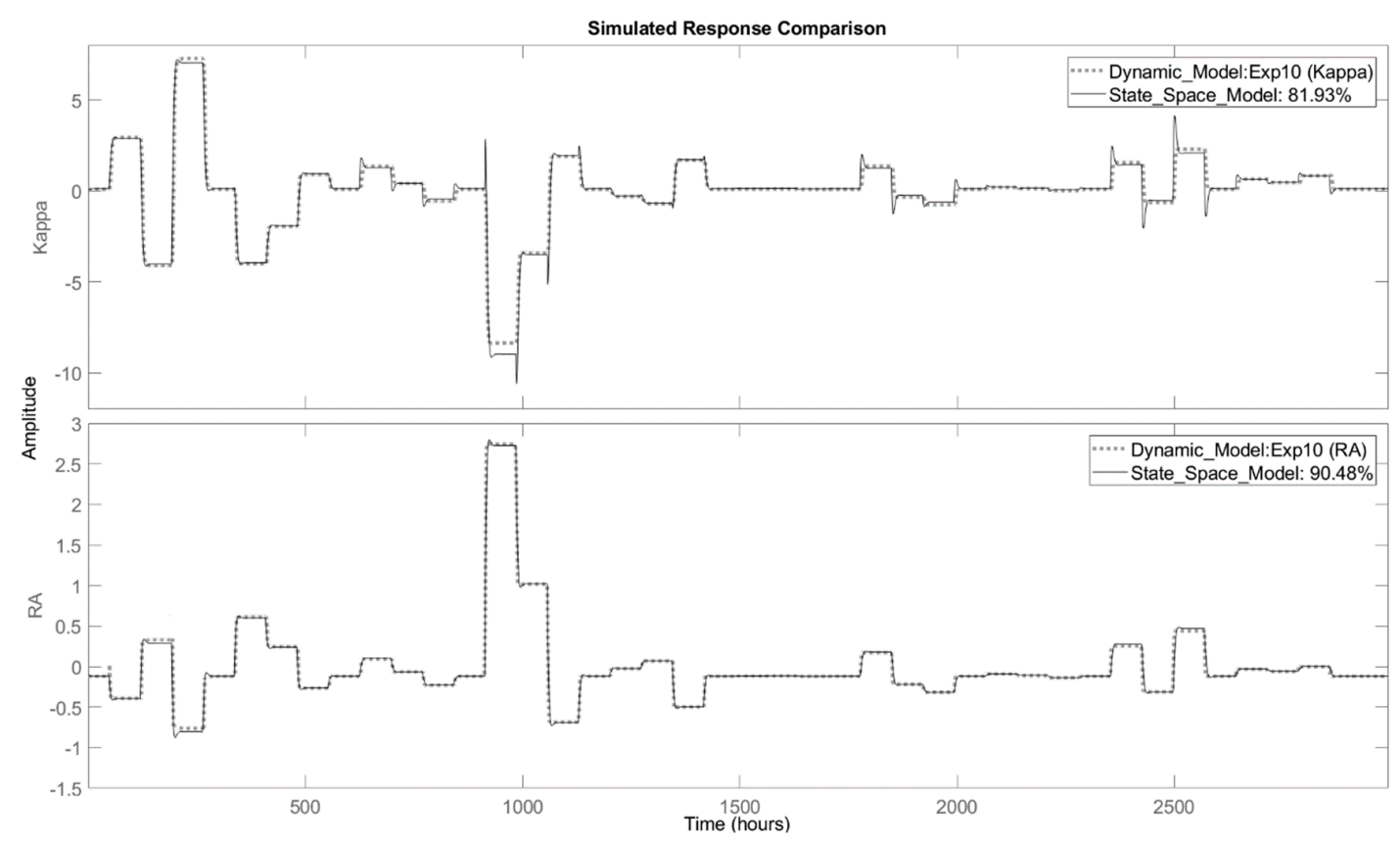

Figure 8. Comparison of the second order state-space model response against the dynamic model.

In practice, all processes are subject to constraints, e.g., physical limits of the actuators, safety limits and operating limits, which need to be included in the optimizer so that the MPC does not violate them. In accordance with the objective of this paper, Kappa number was used as the main controlled output. Hence, the cost function was formulated to minimize the squared errors between the desired set point and the actual trajectory of the blow-line Kappa number. The temperature of the lower heat exchanger was used as the manipulated variable. Subsequently, maximum values for cooking temperature and its rate of change were used as constraints.

\section{Results and Discussion}

To evaluate the performance of proposed MPC approach, three different simulation trials were performed, employing a feedforward MPC (FFMPC), a non-feedforward MPC (NFFMPC) and a decentralized PID controller. MATLAB's PID design tool and MPC Designer toolbox were utilized 
for the simulation trials presented here. For NFFMPC, eight of the most influential input variables (sensor readings), excluding the lignin content were selected as measured disturbances. In FFMPC, along with these input variables, lignin content was added as a measured disturbance. In both cases, the Kappa number and RA were chosen as measured and unmeasured outputs respectively, while lower heater temperature was used as the manipulated variable. Multiple simulations were performed with different MPC parameters, i.e., sampling time, prediction horizon, control horizon and weights in order to examine their effect on the performance of the MPC. Extensive tuning on a trial and error basis was conducted to select the MPC parameters used in this work. No significant performance improvement was observed with further alteration of these parameters. For both FFMPC and NFFMPC, the prediction horizon and control horizon were chosen to be 60 sampling periods and three sampling periods, respectively. The sampling time was set at $15 \mathrm{~min}$ for all cases. MATLAB's PID tuner app was used to tune the PID controllers, which uses a frequency-domain algorithm.

For the presented simulation trials, similar to the actual practice, the reference signal for the blow-line Kappa number was assumed to be a constant. Measurements from actual digester operation were used to capture the process disturbances that usually occur in digester operation. Since the lignin content measurements were not available from the plant data, a repeated sinusoidal variation in lignin content of $\pm 10 \%$ over $12 \mathrm{~h}$ was assumed. Band-limited white noise was also added on the top of the sinusoidal noise. By doing so, it was possible to obtain a realistic measurement noise for lignin content as presented previously in [1]. The validated dynamic model was used to represent the actual digester that was connected to the MPC. To evaluate the robustness of the MPC and mimic the actual industrial conditions, normally distributed white noise were added to the model output Kappa number before feeding it back to the MPC.

The simulated response and control efforts of the MPC and PID approaches are illustrated in Figure 9. For the FFMPC, the lignin content measurement was used as a known measured disturbance. For the NFFMPC, the lignin was used as unmeasured disturbance, hence it was not known to the controller. The dotted line corresponding to the current industrial control represents the base case where actual plant measurements were used as manipulated variable without considering any of the control approaches mentioned above. In current industrial practice, PID controllers are used to control the heat exchangers temperature, where the temperature set points are changed manually by the operator based on experience.

According to Figure 9a, the simulated response for both the MPC approaches show that the controlled variable, i.e., the blow-line Kappa number can follow the desired set point closely without any major deviation. There are some minor deviations, characterized by sudden changes in wood chip flowrate. Overall, the FFMPC provided better control in terms of rejecting disturbances and minimizing the deviation between controlled variable and the set point. The response from NFFMPC is characterized by a sinusoidal oscillation that is contributed by the lignin content variation of the wood chips. The manipulated variable or controller effort for both the MPCs as shown in Figure $9 \mathrm{~b}$ indicate that the controllers can achieve the control objectives without violating the constraints. Moreover, the gap between MPC and manual control curves explain the ineffectiveness of manual control (that is only based on experience) for Kappa number control.

The performance of the PID approach with and without feedback measurement noise is evaluated in Figure 9c,d. As expected, due to the multi-variable nature of the delignification process and the poor robustness against noise, the PID controllers are not adequate for controlling the end-point Kappa number. The output measurement noise results in fluctuations in the manipulated variable that are not achievable due to the rate of change limitations. They also violate the upper limit of the heat exchanger temperature. However, the Kappa number response for PID without noise shows superior performance compared with the current industrial control. It is important to note here that in reality, measured outputs include measurement noises. Hence, implementing a digester Kappa number control based only on the PID scheme requires appropriate filtering of the feedback signal. As summarized in Table 1, in terms of the average output error, the performance of FFMPC was superior to other alternatives. 

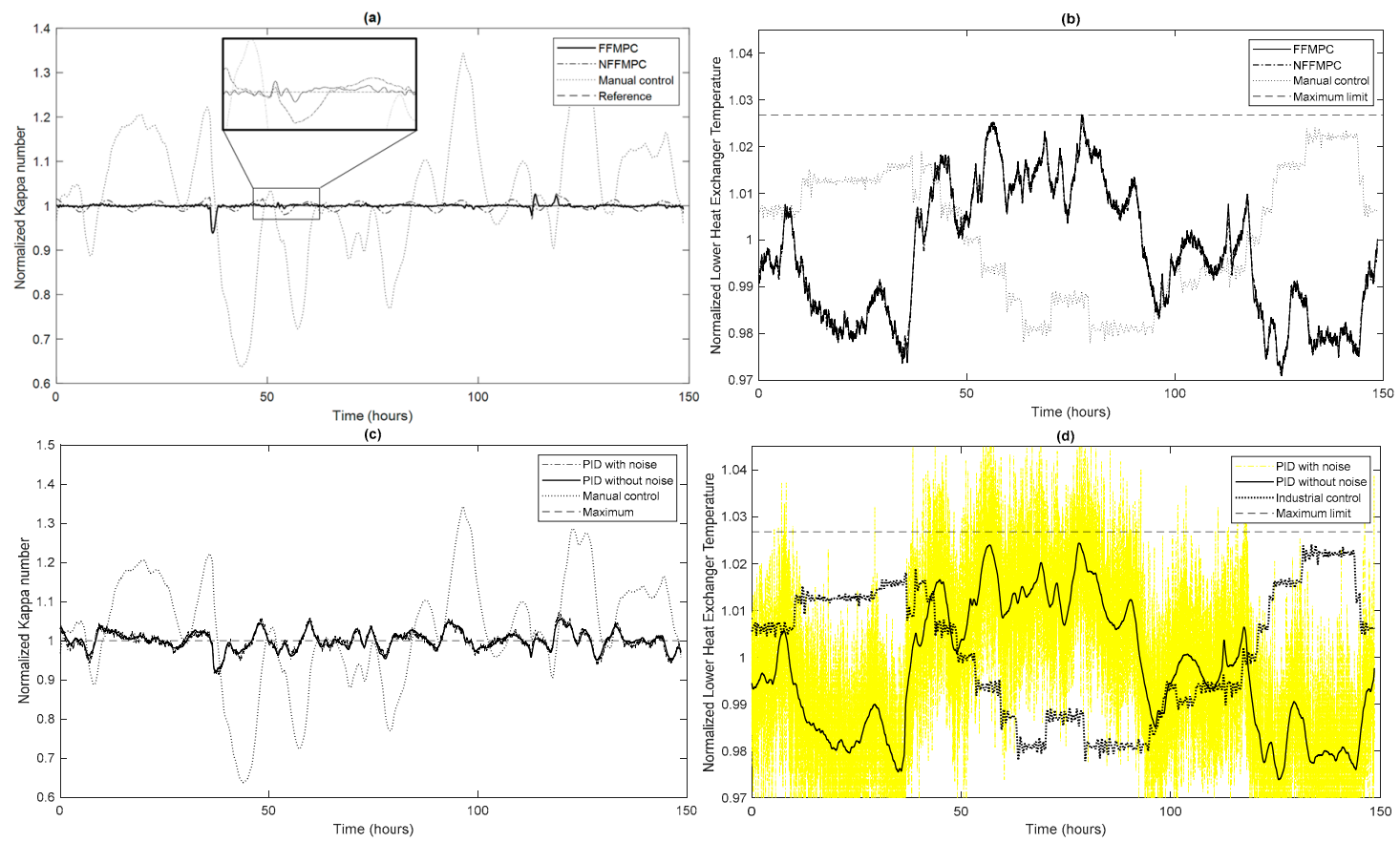

Figure 9. Comparison of MPC (a) response and (b) control effort against the PID (c) response and (d) control effort.

Table 1. Average output error for all the cases.

\begin{tabular}{cccccc}
\hline & FFMPC & NFFMPC & PID (without Noise) & PID (with Noise) & Manual Control \\
\hline Kappa number & 0.1271 & 0.3804 & 0.9781 & 1.0229 & 6.1899 \\
\hline
\end{tabular}

Based on these results, both FFMPC and NFFMPC structures provide improved tracking performance when compared to the current industrial control of a pulp digester, despite the addition of normally distributed white noise to the controlled output. The FFMPC performed better than the NFFMPC by utilizing additional information about the properties of the incoming wood chips. This approach could be even more useful for pulp digesters that need to swing between hard and soft woods alternatively. The average value of the MPC output error was equal to 0.1271 Kappa number, that is, much smaller than the current industrial control scheme (6.1899 Kappa number).

In reality, the set point for blow-line Kappa number usually stayed at a constant value. However, to evaluate the performance of the controllers, a step change in the Kappa number set point was also simulated. As shown in Figure 10, a step change in Kappa number set point was introduced at $28 \mathrm{~h}$. All the controllers were able to follow the set point change acceptably without unusual overshoots.

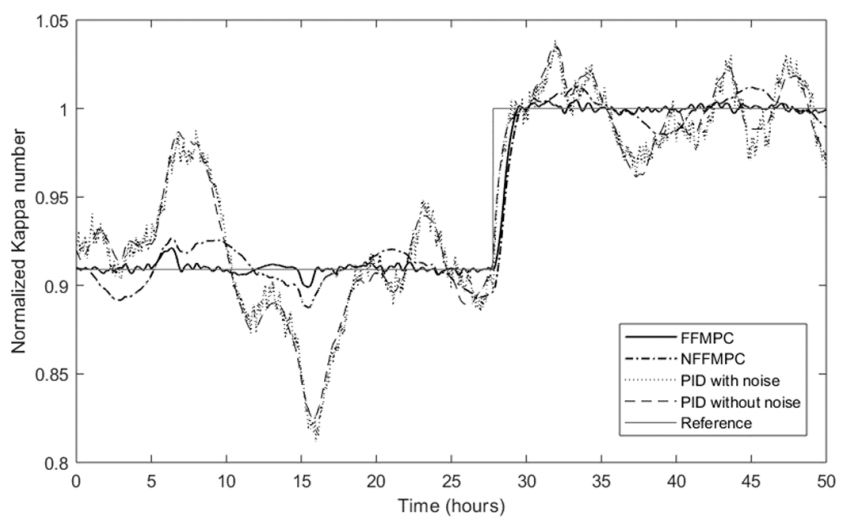

Figure 10. Responses from MPCs and PIDs under step change in the Kappa number set point. 


\section{Conclusions}

A FFMPC approach for Kappa number control of a continuous pulp digester was investigated in this paper. The distinguishing feature of this approach was the use of online lignin measurement as a feedforward signal. Here, the lignin content of the wood chips at the digester inlet was measured online using near infrared spectroscopy. To achieve the aforementioned objective, a dynamic modeling library of a continuous pulp digester was developed in OpenModelica and validated against actual plant measurements. Both the steady state and dynamic response of the developed model were analyzed in detail. To develop the MPC, a state-space model from the validated dynamic model was identified using the subspace identification technique. To evaluate the controller performance, three different control approaches, i.e., FFMPC, NFFMPC and decentralized PID were investigated and compared against the current industrial control approach. Overall, the FFMPC approach provided a smoother response without major oscillations despite the presence of high-frequency output noise. Moreover, the FFMPC approach provided superior tracking performance with smaller average output error when compared with current industrial control and other control approaches. The modeling library developed in this work was sufficiently generic to accommodate modeling of different commercial digesters. This opens up the opportunities for pulp mills to implement MPC for problematic pulp digester control.

Author Contributions: M.R. and K.K. outlined the paper; M.R., designed the case studies, developed all the numerical models, performed the simulations, analyzed the results and wrote the paper; and K.K. and A.A. supervised the work.

Funding: This research was funded by European Commission under Horizon 2020 program, grant number 723523.

Acknowledgments: The authors gratefully acknowledge the financial support from European Commission under Horizon 2020 program, SPIRE-02-2016 through FUDIPO project (http://fudipo.eu/). The authors also thank Erik Dahlquist of Malardalen University and Johan Jansson of BillerudKorsnäs- Gävle mill for their continuous guidance and support.

Conflicts of Interest: The authors declare no conflict of interest.

\section{Notation}

\section{Symbols}

$\begin{array}{ll}\kappa & \text { Kappa number } \\ \gamma & \text { Yield } \\ \eta & \text { Free liquors' volume fraction } \\ \infty & \text { Unreacted part } \\ \text { Letters and Subscripts } & \\ b & \text { Stoichiometric coefficients } \\ c & \text { Chip phase } \\ d & \text { Disturbance vector } \\ e & \text { Entrapped liquor phase } \\ f_{c} & \text { Compaction factor } \\ h & \text { Digester height } \\ i & \text { Series of different components } \\ j & \text { Corresponding control volume } \\ k & \text { Reaction rate constant } \\ l & \text { Free liquor phase } \\ r r & \text { Reaction rate } \\ s & \text { Input vector } \\ u & \text { Input vector } \\ x & \text { State variable vector } \\ y & \text { Output vector } \\ A, B, C, D & \text { State space matrices } \\ A_{1 \& 2, i} & \text { Arrhenius coefficients } \\ E_{1 \& 2, i} & \text { Activation energies } \\ H S^{-} & \text {Hydrosulphide ion } \\ & \end{array}$




$\begin{array}{ll}K & \text { Disturbance matrix } \\ O H^{-} & \text {Hydroxide ion } \\ R & \text { Universal gas constant } \\ S & \text { Weight function for controlled output } \\ T & \text { Temperature } \\ W & \text { Weight function for manipulated variable } \\ X & \text { Component concentrations } \\ \text { Acronyms } & \\ \text { CSTR } & \text { Continuous Stirred Tank Reactor } \\ \text { EA } & \text { Effective Alkali } \\ \text { FFMPC } & \text { Feedforward Model Predictive Control } \\ \text { FT-NIR } & \text { Fourier Transform Near Infrared } \\ H S & \text { Hydrosulphide } \\ M P C & \text { Model Predictive Control } \\ \text { N4SID } & \text { Numerical Subspace State-Space System Identification } \\ N F F M P C & \text { Non Feedforward Model Predictive Control } \\ \text { NIR } & \text { Near Infrared } \\ \text { PDE } & \text { Partial Differential Equation } \\ \text { PID } & \text { Proportional-Integral-Derivative } \\ R A & \text { Residual Alkali } \\ \text { SSID } & \text { Subspace Identification }\end{array}$

\section{References}

1. Rahman, M.; Avelin, A.; Kyprianidis, K.; Dahlquist, E. An Approach For Feedforward Model Predictive Control For Pulp and Paper Applications: Challenges And The Way Forward. In Proceedings of the Paper Conference and Trade Show (PaperCon 2017): Renew, Rethink, Redefine the Future, Minneapolis, MN, USA, 23-26 April 2017.

2. Rahman, M.; Avelin, A.; Kyprianidis, K.; Jansson, J.; Dahlquist, E. Model based Control and Diagnostics strategies for a Continuous Pulp Digester. In Proceedings of the TAPPI PaperCon, Charlotte, NC, USA, 15-18 April 2018.

3. Senbon, T.; Hanabuchi, F. Instrumentation Systems: Fundamentals and Applications; Springer Science \& Business Media: Berlin, Germany, 2013.

4. Seiça, J.C.; Romanenko, A.; Fernandes, F.P.; Santos, L.O.; Fernandes, N.C.P. Parameter Estimation of A Pulp Digester Model With Derivative-Free Optimization Strategies; AIP Publishing: Melville, NY, USA, 2017; Volume 1863.

5. Araújo, A.; Ferreira, J.A.; Fernandes, N.; de Oliveira, P. Using splitting methods in continuous digester modeling. Appl. Math. Model. 2008, 32, 1869-1882. [CrossRef]

6. Smith, C.C.; Williams, T.J. Mathematical Modelling, Simulation and Control of the Operation of a Kamyr Continuous Digester for the Kraft Process; Purdue Laboratory for Applied Industrial Control, Schools of Engineering, Purdue University: West Lafayette, IN, USA, 1974.

7. Michelsen, F.A.; Foss, B.A. A comprehensive mechanistic model of a continuous Kamyr digester. Appl. Math. Model. 1996, 20, 523-533. [CrossRef]

8. Wisnewski, P.A.; Doyle, F.J.; Kayihan, F. Fundamental continuous-pulp-digester model for simulation and control. AIChE J. 1997, 43, 3175-3192. [CrossRef]

9. Bhartiya, S.; Dufour, P.; Doyle, F.J. Fundamental thermal-hydraulic pulp digester model with grade transition. AIChE J. 2003, 49, 411-425. [CrossRef]

10. Kayihan, F.; Bills, A.; Hart, P.W. Mill application of a new continuous digester model. AIChE J. 2005, 51, 2489-2494. [CrossRef]

11. Gustafson, R.R.; Sleicher, C.A.; McKean, W.T.; Finlayson, B.A. Theoretical model of the kraft pulping process. Ind. Eng. Chem. Process Des. Dev. 1983, 22, 87-96. [CrossRef]

12. $\mathrm{Pu}, \mathrm{Q}$. Theoretical and Experimental Studies of the RDH (Rapid Displacement Heating) Pulping Process; University of Washington: Seattle, WA, USA, 1991. 
13. Rantanen, R.A.A. Modelling and Control of Cooking Degree in Conventional and Modified Continuous Pulping Processes; University of Ouluvol: Oulu, Finland, 2006; Volume 68.

14. Grénman, H.; Wärnå, J.; Mikkola, J.P.; Sifontes, V.; Fardim, P.; Murzin, D.Y.; Salmi, T. Modeling the Influence of Wood Anisotropy and Internal Diffusion on Delignification Kinetics. Ind. Eng. Chem. Res. 2010, 49, 9703-9711. [CrossRef]

15. Pourian, B.; Dahlquist, E. CFD modeling of the continuous chemical interaction between the multiphase flows of the pulp and paper digester using the mass transfer scheme. World J. Model. Simul. 2011, 7, 189-205.

16. Nieminen, K.; Paananen, M.; Sixta, H. Kinetic Model for Carbohydrate Degradation and Dissolution during Kraft Pulping. Ind. Eng. Chem. Res. 2014, 53, 11292-11302. [CrossRef]

17. Andersson, N.; Wilson, D.I.; Germgård, U. Validating continuous kraft digester kinetic models with online NIR measurements. Proc. Am. Control Conf. 2002, 5, 3783-3787.

18. Nieminen, K.; Sixta, H. Comparative evaluation of different kinetic models for batch cooking: A review. Holzforschung 2012, 66, 791-799. [CrossRef]

19. Mayne, D.Q. Model predictive control: Recent developments and future promise. Automatica 2014, 50, 2967-2986. [CrossRef]

20. Lindgren, T.; Gustafsson, T.; Forsgren, H.; Johansson, D.; Östensson, J. Model predictive control of the chip level in a continuous pulp digester, a case study. Pulp Pap. Can. 2005, 106, 45-51.

21. Gough, B.; Kay, J.T. Kraft continuous digester effective alkali control. IEEE Ind. Appl. Mag. 1997, 3, 48-53. [CrossRef]

22. Badwe, A.; Satini, R. Continuous Digester Optimization Using Advanced Process Conol; ABB Pulp \& Paper Control Systems Technology Centre: Singapore, 2016; pp. 1-6.

23. Allison, B.J.; Ball, J.B. Constrained model predictive control of blow tank consistency. Control Eng. Pract. 2004, 12, 837-845. [CrossRef]

24. Funkquist. Control of the washing zone in a continuous digester. In Proceedings of the IEEE International Conference on Control and Applications CCA-94, Glasgow, UK, 24-26 August 1994; Volume 1, pp. 513-518.

25. Pringle, T.C.; MacGregor, J.F. Reduced Dimension Control of Dynamic Systems. Ind. Eng. Chem. Res. 2000, 39, 2970-2980. [CrossRef]

26. Silva, C.M.; Biscaia, E.C. Multiobjective optimization of a continuous pulp digester. Comput. Aided Chem. Eng. 2003, 14, 1055-1060.

27. Doyle, F.J., III; Kayihan, F. Reaction profile control of the continuous pulp digester. Chem. Eng. Sci. 1999, 54, 2679-2688. [CrossRef]

28. Michaelsen, T.; Christensen, R.; Lunde, G.G.; Johansson, K. Model predictive control of a continuous Kamyr digester at SCA-Nordliner, Munksund, Sweden. Pulp Pap. Can. Ont. 1994, 95, 146-149.

29. Taha, O.; Dumont, G.A.; Ball, J.B.; Davies, M.S. Model-based Kamyr digester control. In Proceedings of the IEEE Industry Applications Society Dynamic Modeling Control Applications for Industry Workshop, Vancouver, BC, Canada, 26-27 May 1997; pp. 1-5.

30. Roberts, C. Modeling and control of a continuous digester. In Proceedings of the IEEE Industry Applications Society Dynamic Modeling Control Applications for Industry Workshop, Vancouver, BC, Canada, 26-27 May 1997; pp. 6-9.

31. Doyle, F.J., III; Puig, L.J.; Kayihan, F. Grade transition modeling in continuous pulp digesters for reaction profile control. Process Control News (Pulp Pap. Ind.) 2001, 21, 5-6.

32. Padhiyar, N.; Gupta, A.; Gautam, A.; Bhartiya, S.; Doyle, F.J., III; Dash, S.; Gaikwad, S. Nonlinear inferential multi-rate control of Kappa number at multiple locations in a continuous pulp digester. J. Process Control 2006, 16, 1037-1053. [CrossRef]

33. Padhiyar, N.; Bhartiya, S. Profile control in distributed parameter systems using lexicographic optimization based MPC. J. Process Control 2009, 19, 100-109. [CrossRef]

34. Wisnewski, P.A.; Doyle, F.J. Model-based predictive control studies for a continuous pulp digester. IEEE Trans. Control Syst. Technol. 2001, 9, 435-444. [CrossRef]

35. Luppi, P.A.; García, M.P.; Basualdo, M.S. Improvements on model predictive control for a pulp mill process. IFAC Proc. Vol. (IFAC-PapersOnline) 2010, 9, 200-205. [CrossRef]

36. Trung, T.; Allison, B. Advanced online process analyzer for chemical recovery and pulp mill control. O Pap. 2015, 76, 47-56. 
37. Mohammadi, A.R.; Bennington, C.P.J.; Chiao, M. Development of a combined piezoresistive pressure and temperature sensor using a chemical protective coating for Kraft pulp digester process monitoring. J. Micromech. Microeng. 2011, 21, 15009. [CrossRef]

38. Skvaril, J.; Kyprianidis, K.; Avelin, A.; Odlare, M.; Dahlquist, E. Fast Determination of Lignin Content in Feedstock Material for Pulping Process Control and Optimization. In Proceedings of the 8th International Conference on Advanced Vibrational Spectroscopy, Vienna University of Technology, Vienna, Austria, 12-17 July 2015; pp. 1-3.

39. Trung, T.; Downes, G.; Meder, R.; Allison, B. Pulp mill and chemical recovery control with advanced analysers-From trees to final product. Appita 2015, 68, 39-46.

40. Trung, T.; Conroy, B.; Wilson, D. NIR spectroscopy: A paradigm shift in pulp properties measurements. Pulp Pap. Can. Ont. 2015, 24, 24-25.

41. Bajpai, P. Pulp Paper Industry; Elsevier: Amsterdam, The Netherlands, 2015; Volume 1.

42. Ek, M.; Gellerstedt, G.; Henriksson, G. Pulp and Paper Chemistry and Technology. Volume 2, Pulping Chemistry and Technology; Walter de Gruyter: Berlin, Germany, 2009.

43. Galicia, H.J.; He, Q.P.; Wang, J. A reduced order soft sensor approach and its application to a continuous digester. J. Process Control 2011, 21, 489-500. [CrossRef]

44. Amirthalingam, R.; Lee, J.H. Subspace identification based inferential control applied to a continuous pulp digester. J. Process Control 1999, 9, 397-406. [CrossRef]

45. Michelsen, F.A. A Dynamic Mechanistic Model and Model-Based Analysis of a Continuous Kamyr Digester; Department of Engineering Cybernetics, Norwegian Institute of Technology, University of Trondheim: Trondheim, Norway, 1995.

46. Williams, T.J.; Christiansen, T.; Albright, L.F. A Mathematical Model of the Kraft Pulping Process; Technical Report 129; Purdue University, PLAIC, Purdue University: West Lafayette, IN, USA, 1982.

47. Fernandes, N.C.P.; Castro, J.A.A.M. Steady-state simulation of a continuous moving bed reactor in the pulp and paper industry. Chem. Eng. Sci. 2000, 55, 3729-3738. [CrossRef]

48. Puolakka, H.; Kortela, U. Applicability of the chip compaction model in the controlling of the digester. Pulp Pap. Can. Ont. 2005, 106, 40.

49. Kayihan, F.; Gelormino, M.S.; Hanczyc, E.M.; Doyle, F.J., III; Arkun, Y. A Kamyr continuous digester model for identification and controller design. In Proceedings of the 13th World Congress of IFAC, San Francisco, CA, USA, 30 June-5 July 1996; pp. 37-42.

50. Nkansah, K.; Dawson-Andoh, B.; Slahor, J. Rapid characterization of biomass using near infrared spectroscopy coupled with multivariate data analysis: Part 1 yellow-poplar (Liriodendron tulipifera L.). Bioresour. Technol. 2010, 101, 4570-4576. [CrossRef] [PubMed]

51. Lupoi, J.S.; Singh, S.; Simmons, B.A.; Henry, R.J. Assessment of Lignocellulosic Biomass Using Analytical Spectroscopy: An Evolution to High-Throughput Techniques. BioEnergy Res. 2014, 7, 1-23. [CrossRef] 